\title{
Using the imitation model of elementary technological operation at the evaluation of the threshing action of the threshing device
}

\author{
Elena Fisunova ${ }^{1, *}$, Tatiana Lavrenova ${ }^{1}$, and Viktor Zharov $^{1}$ \\ ${ }^{1}$ Don State Technical University, Gagarin square 1, Rostov-on-Don, 344000, Russia
}

\begin{abstract}
The threshing process consists of a number of elementary technological operations, the duration of each of which proceeds during a time of 0.002-0.004 s. surrounded by one bar. In this article we present the calculation of the parameters of the threshing zone using the law of compression. A model of an elementary technological operation has been developed that makes it possible to determine probability of threshing, Calculate the parameters of the working elements of the output zone of the underdrum space of the threshing apparatus of a combine harvester.
\end{abstract}

Combine harvester is a versatile machine for working in any regions. Under the influence of natural factors, the losses exceed the permissible values. Elimination of this kind of deficiency is possible at the stages of the combine harvester manufacturing. In this regard, when designing, there is a need to change the size of the working bodies. The latter applies to the threshing device, on the basis of which the functioning of other systems depends, and as a result the quality of the combine harvester as a whole.

Threshing occurs as a result of impacts at the entrance and rubbing of ears at the output of the threshing space. The rubbing phases include rapid contraction with shear and removal of loading from a portion of the bread mass. When creating new machines, it is actual to calculate the operating parameters of the underdrum exit zone, as one of the main structural elements of the threshing device..

An analysis of the plant mass (heap of chaff and straw) showed that, when the combine harvester is close to the optimal operating mode, a considerable fraction of the losses are formed by a ragged ear. Moving chaotically in the threshing space, undergoing shock impacts, the end parts of the ears lose grain, falling apart.

Based on the results of measurements by the authors [1-5] it is known that in the threshing process, the spikes are subjected to an average normal compression force of about $9.81 \cdot 10$ $\mathrm{Pa}$.

According to the N.I. Panteleev research [6], the normal compression force for threshing the whole ear is $34.34 \cdot 10 \mathrm{~Pa}$. In accordance with the experimental data, the threshing theory

*Corresponding author: fis62@mail.ru 
was developed [1], which is based on the fatigue character of the destruction of the grain-ear connection with multiple application of forces less than critical. Such forces, initiated in the layer with a single passage of the flail over a portion of the bread mass moving along the smooth surface of the underdrum space, constitute an elementary technological operation of threshing.

A number of authors $[2,4]$ have established that the interaction of a flail with a bar has an impulsive character. Threshing becomes possible only in the area of an isolated bar, provided that sufficient compression forces develop in it. Thus, an elementary technological operation is the effect on the connection of grain with the ear in the nearest surroundings of the underdrum bar when the flail passes over it. We specified the results of the experiment of N.I. Panteleyev [6], the object of threshing which was a whole ear. As a result of conducted experiments with ears, threshed by $70-80 \%$, it was established that sufficient pressure for threshing was chosen, varying in the range of $6.87 \cdot 10 \mathrm{~Pa}-9.22 \cdot 10 \mathrm{~Pa}$. However, a single compression of a portion of the plant mass when it is overtaken by a flail does not guarantee threshing due to the ribbed underdrum.

The process of compression the plant mass in the surroundings of a detached bar occurs instantaneously. To calculate the compression forces, the scheme (equivalent) shown in Figure 1 is used.

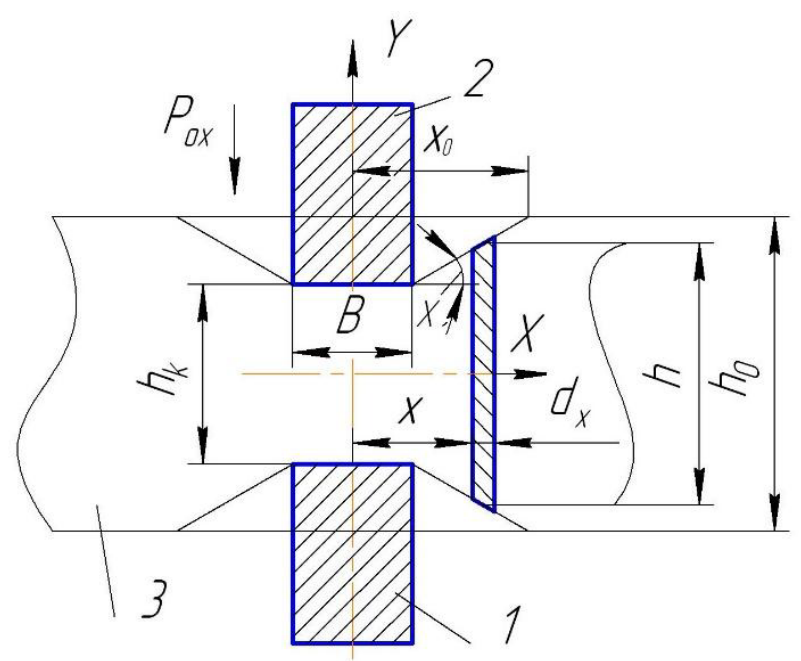

Fig. 1. Scheme (equivalent) for calculating compression forces: 1 - bar, 2 - flail, 3 - plant mass layer.

The pressure in the gap directly between the whip and the bar will be equal to

$$
P_{1}^{u d}=\mathrm{C} * \gamma_{k}^{m}
$$

The ratio for calculating the pressure outside the gap, depending on the timing of the convergence of the flail with the bar, has the form:

$$
P(t)=C *\left[\gamma_{0} *\left(\frac{\left(v * \tau_{\varphi}\right)^{2}+h_{k}^{2}}{\left(\nu *\left(\tau_{\varphi}-t\right)\right)^{2}+h_{k}^{2}}\right)^{0.5}\right]^{m}
$$

The current time value can be found from the expression:

$$
t=\tau_{\varphi}-\frac{\omega}{v}
$$


where

$$
\omega=\left[\left(\frac{c}{P(t)-e^{m}}\right)^{2} * \gamma_{0}^{2} *\left(h^{2}+\left(v * \tau_{\varphi}\right)^{2}\right)-h^{2}\right]^{0.5}
$$

For $t=\tau_{\varphi}$ formulas (1) and (2) give the same results.

The calculation showed, for example, that for a flail width of $0.008 \mathrm{~m}$ and a distance between the flail and the bar $0.01 \mathrm{~m}$, the pressure in both cases was $9,67 * 10^{4} \mathrm{~Pa}$.

The average pressure according to the experimental data for the complete destruction of the underthreshed ears is $8,04 \cdot 10^{4} \mathrm{~Pa}$.

After the beginning of the pressure increase, the connection between the grain and the spike falls into the zone of guaranteed destruction. The time of pressure rising is obtained from formula:

$$
t_{1}=\tau_{\varphi}-t_{s}
$$

and the width of the guaranteed threshing zone is:

$$
s=B+2 * v * t_{1}
$$

The probability of threshing for one compression when overtaking the flail of a portion of plant mass is calculated by the formula:

$$
\text { ver }=\frac{s}{s_{1}}
$$

Where $s_{1}$ - bars step.

The number of incompatible equally probable and constituting the complete group of events necessary for guaranteed threshing is equal to:

$$
C_{h}=\frac{1}{v e r}
$$

The next event after the event will occur after a period of time:

$$
t=\frac{\left(v * t_{b}\right)}{\left(v-v_{s}\right)}
$$

A new meeting of the flail with a portion of the plant mass will take place on an elongation from the first:

$$
s_{t}=v_{s} * t_{v}
$$

The length of the rubbing zone is determined from expression:

$$
L_{d}=C_{h} * S_{t}
$$

Calculation showed that when $\tau_{\varphi}=0.002 \mathrm{~s} ., v=30 \mathrm{~m} / \mathrm{s}, v_{s}=7.5 \mathrm{~m} / \mathrm{s}, B=0.008 \mathrm{~m}$, $\gamma_{0}=245 \mathrm{~N} / \mathrm{m}^{3}, h_{k}=0.008 \mathrm{~m}, s_{1}=0 / 006 \mathrm{~m}, C=0 / 1281 \cdot 10^{4}, m=2 / 195$, time $t_{v}=0 / 00197$ $\mathrm{s}$, and the probability of threshing for one compression is $0 / 163$. If the number of events necessary is $C_{h}=6 / 12$ the extent of the rubbing zone is $L_{d}=0 / 48 \mathrm{~m}$. This value corresponds to $66 / 8^{\circ}$ for the underdrum of the combine harvester "Don-1500" with a grip angle $\alpha=130^{\circ}$ and radius $R=0,41 \mathrm{~m}$.

With working gaps at the inlet and outlet of the underdrum $(20 / 3 \mathrm{~mm})$, the current gap of $10 \mathrm{~mm}$ will correspond to a zone of rubbing of $0.46 \mathrm{~m}$. All this indicates a good 
approximation of the calculated value to the value established by the practice of many years of testing [7-8].

\section{Summary}

Elementary technological operation of threshing is realized by the impact of the flail in the immediate vicinity of a separate underdrum bar through the underthreshed ear for $10-30 \%$. From the condition of complete threshing, expressions were obtained to justify the rational parameters of the underdrum exit zone. Simulation of an elementary technological operation allows us to track the results in a graphical form.

\section{References}

1. E.I. Lipkovich, Processes of threshing and separation in threshing machines of combine harvesters, 165 (1973)

2. G.A. Kuzin, Intensification of threshing and separation process in threshing machines of combine harvesters, 505 (1989)

3. D.N. Borodin, I.V. Malakhovski, ISKNCVS, On the parameters of the flow of the grain mass in the concavity of the threshing device of the combine, 2, 14-19 (1984)

4. N. I. Klenin, Research of the milling and separation of grain, 424 (1977)

5. N.I. Chursin, Research of technological process in rotary threshers of harvesting machines, 295 (1970)

6. N.I. Panteleev, Investigation of physical and mechanical properties of spiked crops as an object of threshing, 156 (1973)

7. M.A. Pustigin, Theory and technological calculation of threshing devices, 95 (1948)

8. D.K. Rebrilov, SiS, Injury of wheat seeds during threshing process, 5, 60-65 (1971) 